\title{
Del lino europeo al cedro americano. Los materiales vegetales en los soportes de la pintura colonial sudamericana
}

\author{
Damasia Gallegos, Ana María Morales, Dolores González Pondal, Gabriela Siracusano, Fernando \\ Marte
}

\begin{abstract}
Resumen Desde una perspectiva histórica y a partir de la materialidad de dos piezas pictóricas, esta investigación pretende reflexionar sobre materiales, técnicas, usos y costumbres en la pintura colonial. Sobre un corpus de más de cuatrocientas obras del período colonial intervenidas, la propuesta implica analizar los soportes principales y accesorios de dos obras sudamericanas, San Luis Gonzaga y San Juan Nepomuceno, pertenecientes a la Iglesia de San Ignacio en la ciudad de Buenos Aires, Argentina.
\end{abstract}

Palabras clave: Pintura colonial, lienzos, bastidores

\section{From the European linen to the American cedar. The vegetal materials in the South American colonial paintings supports}

Abstract: From a historical point of view and based on the materiality of two pictorial pieces this research aims to reflect about colonial's painting materials, resources, applications and techniques. After working on a four thousands corpus of colonial paintings, the proposal involves the canvas and strainers study of two South American paintings, San Luis Gonzaga and San Juan Nepomuceno, belonging to the Church of San Ignacio in Buenos Aires city, in Argentina.

Keyword: Colonial painting, canvas, strainers

Do linho europeu ao cedro americano. Os materiais vegetais nos suportes da pintura colonial Sul-Americana

Abstract: A partir de uma perspetiva histórica e da materialidade das peças pictóricas, esta investigação pretende refletir sobre materiais, técnicas, usos e costumes na pintura colonial. Sobre um corpus de mais de quatrocentas obras do período colonial intervencionadas, a proposta implica analisar os suportes principais e acessórios de duas obras Sul-Americanas, San Luis Gonzaga e San Juan Nepomuceno, pertencentes à Igreja de San Ignacio na cidade de Buenos Aires, Argentina.

Keyword: Pintura colonial, telas, grades 


\section{Introducción}

En una pintura de caballete una gran proporción de sus materiales constitutivos son de origen orgánico. Aquellos estratos más visibles como los fondos, capa pictórica y barnices alternan compuestos de distintas procedencias y varían -entre otras cosas- según las técnicas elegidas, las épocas o lugares de ejecución. En cuanto a la estructura de sostén de una obra, excluyendo metales, piedras o cueros, los soportes de la pintura se reducen básicamente a materiales celulósicos.

En el caso de las piezas sudamericanas coloniales, el lienzo tensado en un bastidor de madera fue la estructura más utilizada. La tradición de la pintura sobre tabla no tuvo eco significativo en estas latitudes. Tampoco el papel o el cartón constituyeron materiales divulgados en pinturas de ese período. La tela fue, entonces, el soporte sobre el cual los pintores plasmaron sus obras. Algunos materiales fueron importados de España, pero en gran medida los artistas se valieron además, de recursos locales.

Durante el lapso de los años 1987 y 1997, más de 400 obras coloniales fueron estudiadas y restauradas en la Fundación TAREA (TAller de REstauración de Arte) en la ciudad de Buenos Aires, Argentina. La gran mayoría de los soportes pictóricos, tanto aquellos cuzqueños como locales, estaba constituida por textiles de algodón hilado a mano, de tramas irregulares y abiertas. En muchos casos los lienzos confeccionados en lino, cáñamo o yute, que habían servido para otros fines como envolturas de mercancías, se reciclaban y los artistas los reutilizaban con el mismo propósito. Sin embargo la tela de lino, material por excelencia como soporte para pintar, fue un recurso de los pintores más prósperos, debido a su alto costo. Asimismo, en cuanto a los bastidores sobre los que se tensaban las telas, estaban confeccionados con maderas autóctonas, ensamblados con tarugos del mismo material, clavos o tachuelas de forja (Burucúa et al. 2000: 20).

Este trabajo se propone analizar los soportes principales y accesorios de dos pinturas coloniales procedentes de la iglesia de San Ignacio de Buenos Aires -San Luis Gonzaga y San Juan Nepomuceno-y realizadas durante el siglo XVIII. ${ }^{1}$

\section{Antecedentes}

En la década de los 90, en Buenos Aires, la Fundación TAREA concentró toda su idoneidad en restaurar pintura del período colonial del patrimonio argentino. Esto abarcó aquellas piezas que fueron llevadas a cabo dentro del actual territorio del país o fuera de él pero que formaron parte del marco cultural colonial y de las primeras décadas de la república. Existieron también en esta zona, obras traídas de España y algunas de Italia y Flandes. Aun así, la gran mayoría, provenía de talleres instalados en las grandes ciudades virreinales como Cuzco. No obstante, en el último tiempo del mencionado período, la producción local se hizo fuerte, tanto por manos de discípulos de maestros de los grandes centros como de pintores europeos que se instalaron en la región (Jáuregui, Penhos 1999: 61).

En cuanto a la técnica y los materiales de la pintura colonial TAREA significó, sin duda, un punto de inflexión. La literatura hasta ese momento en Argentina, sobre este tema, era escasa y la Fundación hizo un valiosísimo aporte. Sin embargo, dadas las vistosas características de los pigmentos, colorantes o barnices los estudios más exhaustivos se centraron en estos estratos mientras que el resto de la estructura pictórica quedó relegada. Si bien la TAREA de los años 90 relevó tanto las telas como los bastidores de las pinturas intervenidas en el taller, no hubo entonces, un estudio sistemático de estos elementos. Dentro de los cuatrocientos cuadros que fueron intervenidos durante esos diez años, solamente trece casos eran tablas y dos metales, el resto de las pinturas estaban pintadas sobre telas, básicamente tejidos de lino y algodón, tensadas en un bastidor de madera (cf. Burucúa et al. 2000: 227-236). Es importante remarcar que, en la tradición de la restauración, cuando una obra llega al taller con problemas estructurales la alternativa inmediata es el reemplazo del bastidor y el refuerzo de su soporte mediante un entelado (cf. Rostain 1981). Estos tratamientos tradicionales, fundamentales para la preservación de las obras, aseguran la conservación en el tiempo pero lamentablemente eliminan un gran caudal de información sobre insumos, recursos, tránsito y manufactura de los soportes pictóricos. Afortunadamente estas prácticas de restauración, que en un momento eran casi de rutina, fueron mermando y ya en aquellos años comenzaron a implementarse algunas alternativas que lograron suplir con éxito este tipo de intervención considerablemente invasiva (cf. Roche 2003).

El inicio del proyecto de San Luis Gonzaga y San Juan Nepomuceno se vio favorecido por la metodología implementada del trabajo interdisciplinario $y$, en lo que se refiere a la conservación, la aplicación de la mínima intervención. Citando a Puccio Speroni -conservador del Museo Nacional de Dinamarca-, "el concepto minimizar se refiere a toda intervención que tiende a reducir al mínimo el stress y los daños colaterales que puedan causarse a la pieza antes, durante y después del tratamiento y en consecuencia también el término minimizar implica mejorar y si es posible eliminar los equívocos y excesos producidos en restauraciones del pasado" (Speroni 2005: 37).

En cuanto a la datación y procedencia de las piezas, ambas aparecen mencionadas en el Inventario realizado en ocasión de la expulsión de los jesuitas, documento que nos indica que las mismas fueron ejecutadas antes de $1767 .^{2}$ Su presencia en la iglesia de San Ignacio de Loyola, junto con otras piezas procedentes de las misiones jesuíticas guaraní, pinturas y retablos confeccionados por artistas tales como Miguel Aucell, Isidro Lorea y Gaspar Hernández, hablan del escenario artístico de Buenos Aires de fines del XVIII y principios del XIX y de una ciudad puerto por la que ingresaban todo tipo de mercaderías. 
En primera instancia la pintura de San Luis se presentó como un caso sobre el cual era fundamental recuperar su carácter documental. En consecuencia, cada decisión a tomar debía estar supeditada a preservar sin interferir el aporte de datos e información que la pieza pudiera brindar. El sesgo inculcado a la restauración, pensando en primer lugar en el documento histórico que representaba la pintura, condujo el curso del trabajo hacia diferentes horizontes y generó la aplicación de técnicas analíticas, metodologías y materiales alternativos que luego fueron trasladados también, al caso de San Juan Nepomuceno. Estas dos obras fueron el motor propulsor para un estudio que involucra muchas variables. En este artículo nos limitaremos a exponer el tema de sus soportes siendo simultáneamente el comienzo de un estudio sistemático de lienzos y bastidores utilizados a lo largo del periodo colonial intentando establecer orígenes y épocas de las telas. La heterodoxia de materiales usados en la región no permite fijar patrones, pero la calidad de las fibras, tanto de las telas como de las maderas, y la manufactura empleada puede ayudar a ubicar temporal y espacialmente a este tipo de piezas.

En el caso de las telas, la identificación de las principales fibras que la componen, la clasificación de los distintos ligamentos empleados, las costuras utilizadas para las uniones y la manera de tensado proveen un bagaje de información no siempre tenido en cuenta. Es importante remarcar que las fibras que forman las telas constituyen las unidades básicas a partir de las cuales los lienzos son confeccionados y pueden clasificarse, dentro del período estudiado, en fibras de origen natural, -animal y vegetal. Es entonces que se puede definir una tela como el entrecruzamiento de hilos, compuesto por la urdimbre, cuya disposición en el telar es longitudinal y la trama que, a su vez, la entrelaza siguiendo una dirección horizontal. De este modo, los tipos de entrecruzamiento dan origen a los variados ligamentos que caracterizan a una tela y de la misma manera, el tipo de hilo y de tejido influyen significativamente en el comportamiento y características mecánicas de la misma (cf. Gordon Cook 1993). Con el transcurrir del tiempo, estas cualidades mecánicas se modifican y en consecuencia, las propiedades del lienzo como soporte pictórico también, generando la aparición de desgastes, roturas y deformaciones (cf. Mecklenburg, Tumosa, 1991). Estos cambios se deben, por un lado, a la condición de vicio inherente propia del material orgánico y por otro, a factores ambientales como la luz, la humedad, la temperatura y gases contaminantes, así como también a la manipulación, de manera tal que dichos agentes acompañan a la obra en su inevitable envejecimiento (cf. Greaves et al.1995).

Desde el siglo XVI el lienzo tensado sobre el bastidor ha sido el soporte preferido de los artistas, aunque el menos estudiado. La imposición definitiva de la tela como soporte pictórico reemplazando a la tabla de madera se inició en el siglo $\mathrm{XV}$, aun cuando se sabe de la existencia de telas pintadas con anterioridad, (Young, 2012: 126).
Sus cualidades de flexibilidad, ligereza, resistencia, transporte y adaptación a grandes formatos favorecieron esta imposición. Antiguamente, las primeras telas, a modo de tapices, eran pintadas sobre un apresto previo o directamente sobre el lienzo crudo, sin la presencia de un bastidor. Este tipo de piezas fueron conocidas en España como sargas y en Alemania como Tüchlein. Algunas de ellas ejercían una función decorativa temporal que, a modo de telones, cubrían los altares dependiendo la conmemoración (cf. Villers, 2000).

Con todo, a medida que se suceden los siglos, las telas han tenido una evolución técnica y morfológica determinante tanto para el desarrollo de la pintura como para su conservación. El estudio del soporte textil contribuye además, al aporte de evidencias sobre la historia, manufactura de cada época y autoría, como así también, asiste en la toma de decisiones del tratamiento, para su preservación. Es por ello que para poder trabajar dentro de este campo es fundamental conocerla en profundidad sabiendo que gran parte de la estabilidad de una obra es consecuencia del comportamiento de su soporte.

\section{El caso de San Luis Gonzaga}

El templo católico más antiguo que se conserva en la ciudad de Buenos Aires, es la Iglesia de San Ignacio de Loyola. Fue fundada por los jesuitas en el siglo XVII y declarada Monumento Histórico Nacional en 1942. Duranteel gobierno del General Juan Domingo Perón, en 1955, varias iglesias de la capital argentina sufrieron incendios intencionales. En ese momento imágenes originales se quemaron y diversos objetos fueron saqueados. Aun cuando el edificio fue intervenido en sucesivas ocasiones, en el año 2011, se llevó a cabo la recuperación del templo y casualmente en uno de los altares laterales, fueron descubiertos los retazos disgregados de una antigua tela. Dentro de la mesa del altar y bajo varias capas de tierra y escombros se encontraban semi enterrados ocho pedazos de lienzo de distintos tamaños y formas [Figura 1]. Una vez fuera de la fosa, en cada uno de los deformados fragmentos se adivinaba una imagen de gran formato pintada sobre tela. A pesar de la situación desfavorable a la que había estado sometida la obra, era llamativo advertir, que la superficie pictórica aún estaba adherida al soporte de tela. Existían mermas y desprendimientos pero las áreas pintadas eran relevantes y se presumía posible descubrir, debajo del velo de tierra, un retrato de grandes dimensiones.

Una vez en el taller, nuestro equipo pudo identificar en esa ruina la imagen de San Luis Gonzaga considerada perdida por la historiografía vernácula desde los años cuarenta. Las características formales y estilísticas de la obra condujeron al análisis de los inventarios relativos a los jesuitas. Una particularidad fundamental encontrada y que explica en parte el grave deterioro del lienzo, fue la función que cumplía el cuadro en el altar. Ubicado en la hornacina del mismo, la pintura formaba parte de uno de los retablos 


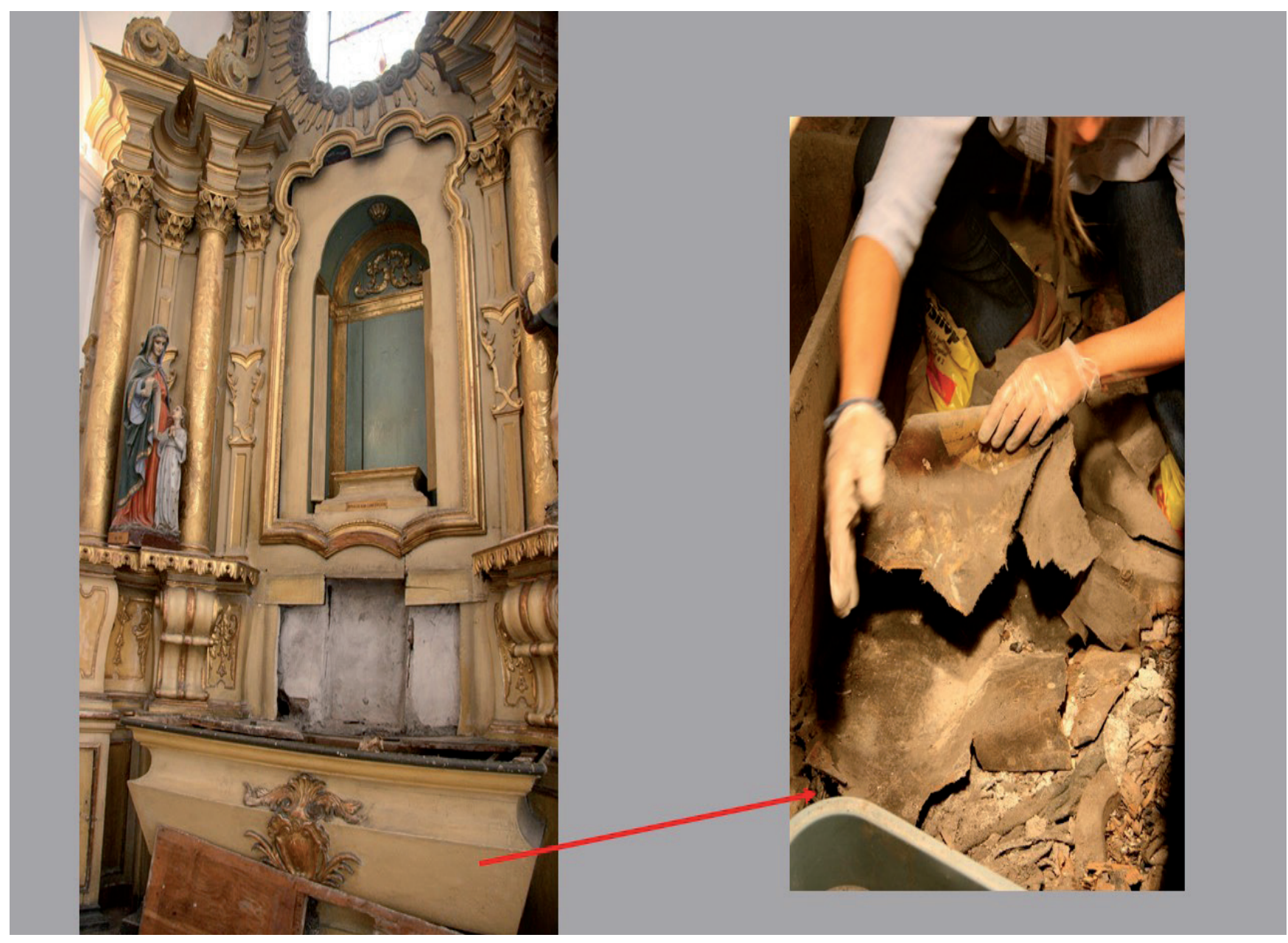

Figura 1.- Hallazgo de los fragmentos de pintura dentro de la mesa del altar de la Inmaculada Concepción. Iglesia de San Ignacio, Buenos Aires.

de tramoya de la iglesia (Ribera y Schenone 1944: 334). Toma este nombre por el mecanismo accionable que actúa cerrando por completo el retablo, mediante un cuadro a modo de telón o cortina, siendo la función de estos lienzos idéntica al telón de boca de un escenario de teatro (cf. Bonet Blanco 2001). Según la liturgia, la imagen podía estar a la vista o mantenerse oculta a través de este sistema que todavía hoy, en el altar adyacente de San Juan Nepomuceno está vigente. En estos altares, el lienzo ocupaba un espacio destinado ex profeso por el constructor del retablo que quedaba entre el nicho y el marco del mismo. Por este motivo la tela debía ser colocada antes de la terminación total del altar y su disposición variaba según la arquitectura. Es así como en algunos casos, la pintura corría de derecha a izquierda o a la inversa, y en casos especiales de abajo hacia arriba como es nuestro San Luis. Seguramente en alguna oportunidad la pieza quedó abajo y roto el mecanismo ya no volvió a subir, deteriorándose tanto por el exceso de humedad como también por la intervención del hombre.

Con todo, aun cuando en el conjunto de fragmentos encontrados en el altar, se podía reconocer lo que había sido un objeto destinado a la práctica religiosa, era inevitable considerar el lienzo de San Luis Gonzaga como una verdadera ruina. Sin embargo esta ruina constituía una pieza de interés cultural, testimonio de hechos histórico- documentales, artísticos, institucionales, religiosos. El carácter de la obra exigía la aplicación de un criterio de restauración que respetara al máximo la mínima intervención (cf. Weddigen 2005). Esta decisión obligaba a buscar técnicas y materiales que destacaran este significado ennobleciendo el documento sobre su función original como objeto de culto u obra de arte. La propuesta implicaba evitar encubrir o velar hechos pasados priorizando esta nueva acepción de documento histórico (cf. Kirby 2005). Con tal motivo la restauración se limitó simplemente a unir todas las piezas mediante puentes de fibra de cáñamo, remover el barniz oxidado que distorsionaba la imagen y reforzar la estructura con un entelado completamente reversible. Para ello se eligió el empleo del sistema nap bond (cf. Mehra 2001) método en el cual se restringe tanto el uso de humedad como la cantidad de adhesivo utilizada minimizando, de ese modo, cualquier alteración de la pieza y obteniendo un entelado fácilmente removible. Asimismo, se decidió que las grandes mermas se mantuvieran de ese modo sin reponer el soporte faltante destacando, de esta manera, la imagen recuperada. Fue entonces como la restauración de los fragmentos permitió recobrar una imagen legible que, aún con las enormes lagunas, logra evocar la representación de San Luis Gonzaga (cf. Morales et al. 2016). [Figura 2] 


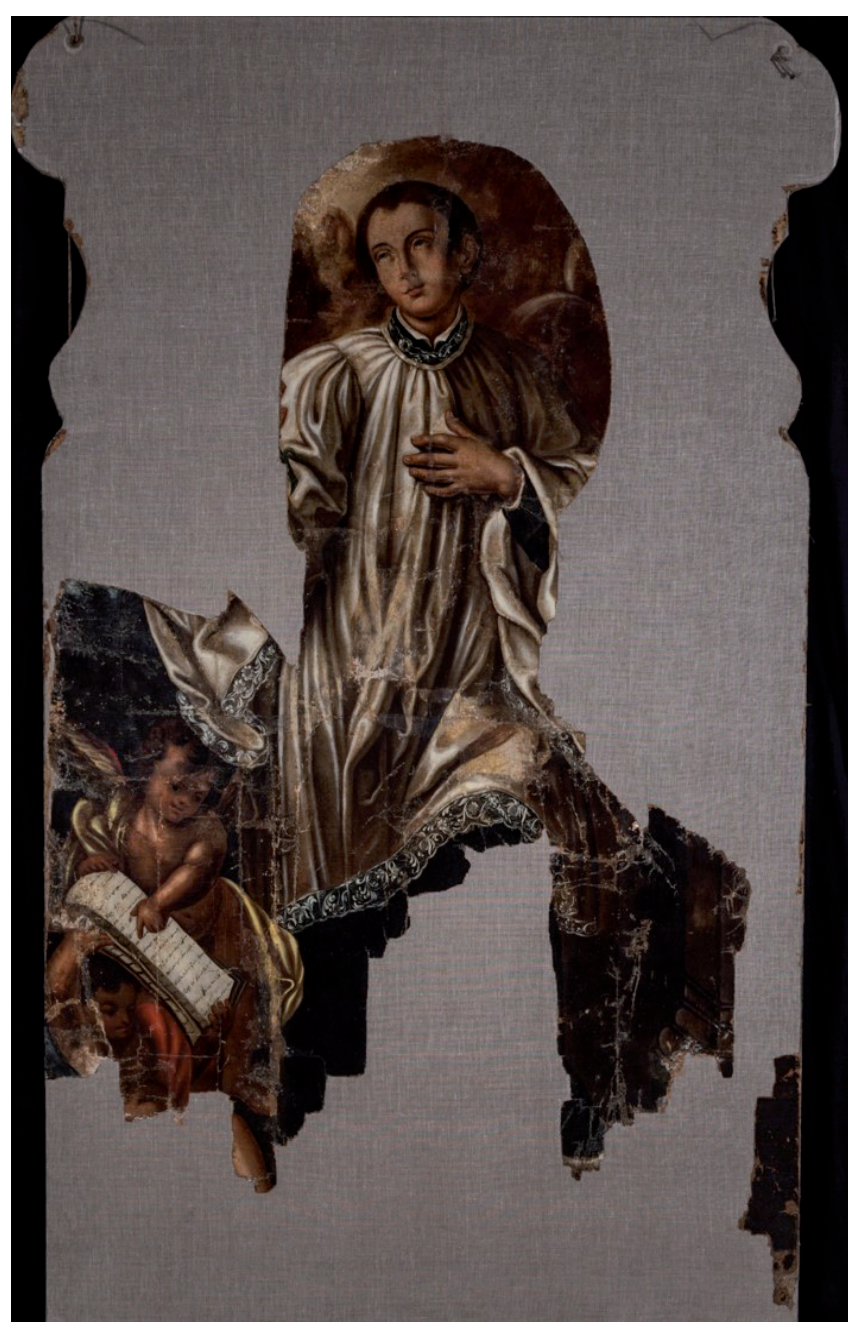

Figura 2.- San Luis Gonzaga luego de la intervención. (IIPCTAREA).

Es importante destacar que, previo a la intervención, se tomaron muestras de las fibras textiles y de la capa pictórica de los fragmentos encontrados. Se observó en todas las telas una trama relativamente cerrada, constituida por hilos bastante regulares entre sí, de ligamento plano con un entrecruzamiento de $1 \times 1$. La identificación por microscopía óptica confirmó la presencia de fibras de lino, tanto en la trama como en la urdimbre. La densidad variaba según el recuento, entre 144 y 168 hilos x cm.2 Asimismo, el lienzo de San Luis estaba formado, al menos, por dos piezas de tela cosidas a mano con una puntada simple tomada por el borde de ambos textiles, para no generar volumen, a modo de un surfilado (cf. Bruquetas Galán 2002: 235). Antonio Palomino define esta costura como: "punto por cima, con hilo sencillo fuerte y delgado para que no haga bulto y no cogiendo de las orillas del lienzo más que el último hilo o a lo más los dos, y el punto no apretado sino sentado no más; y de esta suerte queda la costura en estirando el lienzo tan disimulada, que apenas se conoce" (Palomino 1944: 49). [Figura 3]

Cabe remarcar que, a diferencia del algodón, el lino que se utiliza para textiles se cultiva en regiones subtropicales

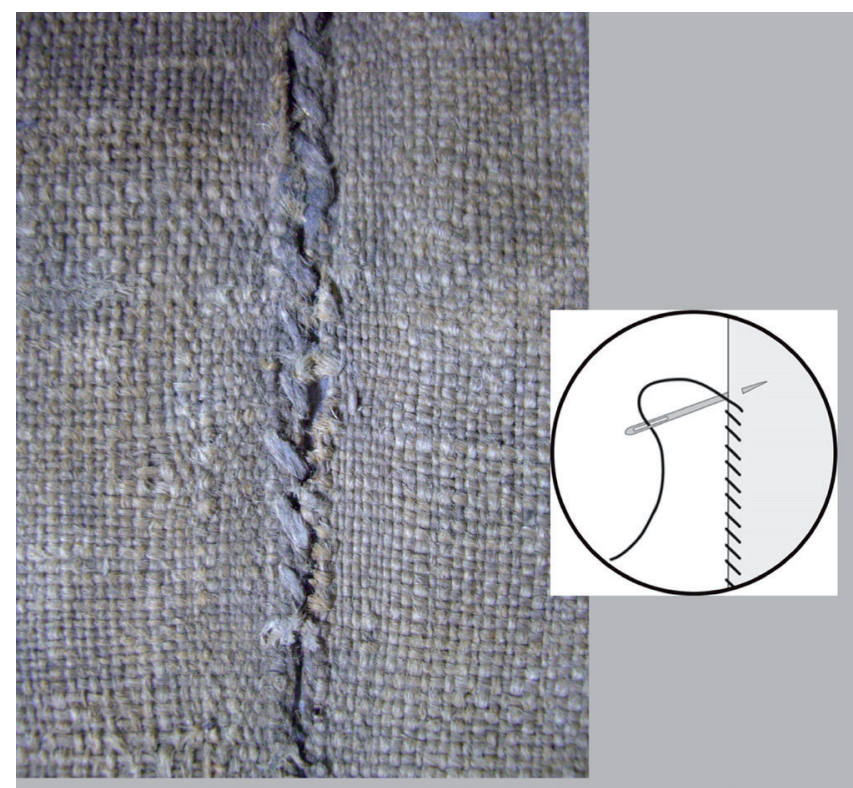

Figura 3.- Detalle de la costura de la obra de San Luis Gonzaga que muestra el punto por cima descripto por Palomino.

o al norte de las zonas templadas debido a que su resistencia a las heladas es muy inferior a la del trigo y otros cereales. Es por esta razón que este tipo de materia prima se obtenía en esta zona únicamente mediante importación. Asimismo, tanto la terminación como el acabado del soporte de San Luis delatan una manufactura de hilado mecánico descartando la posibilidad de una tela tejida en un telar local como aquellas encontradas en las pinturas provenientes del noroeste argentino (Burucúa et al. 2000: 20). Estos indicios, abonan la idea de una procedencia del otro lado del Atlántico. Un comercio fluido con España de estos materiales sumado a la carencia de fábricas textiles en la región indicaría que una pieza de lino con estas características fue traída del viejo continente (cf. Vicens Vives 1972).

Por otro lado, el hallazgo del bastidor original del santo jesuita, en la sacristía de la iglesia, significó otro dato fundamental. Este descubrimiento permitió inferir el tamaño original de la pintura y la ubicación espacial exacta de los retazos, gracias al remanente de los bordes de tela que permanecieron adheridas a la estructura [Figura 4]. Acerca de este peculiar bastidor, se pudo observar que estaba compuesto por 6 piezas prolijamente acabadas, que formaban las curvas cóncavas y convexas. Es interesante remarcar que el tallista necesita moldear varias piezas para obtener el perfil lobular que se encuentra en los extremos superiores y que, aun cuando se refleja pericia en el trabajo realizado, el bastidor presenta ligeras asimetrías. Por su parte, los ensambles son de media madera fijos, encolados y reforzados con tarugos. El cabezal superior, incompleto en su parte media a causa de la acción del fuego, presenta dos perforaciones en cada uno de los muñones parcialmente carbonizados. Por allí pasaba el cordel -del cual todavía se conserva un pequeño tramo- para el ascenso y descenso de la pintura. 


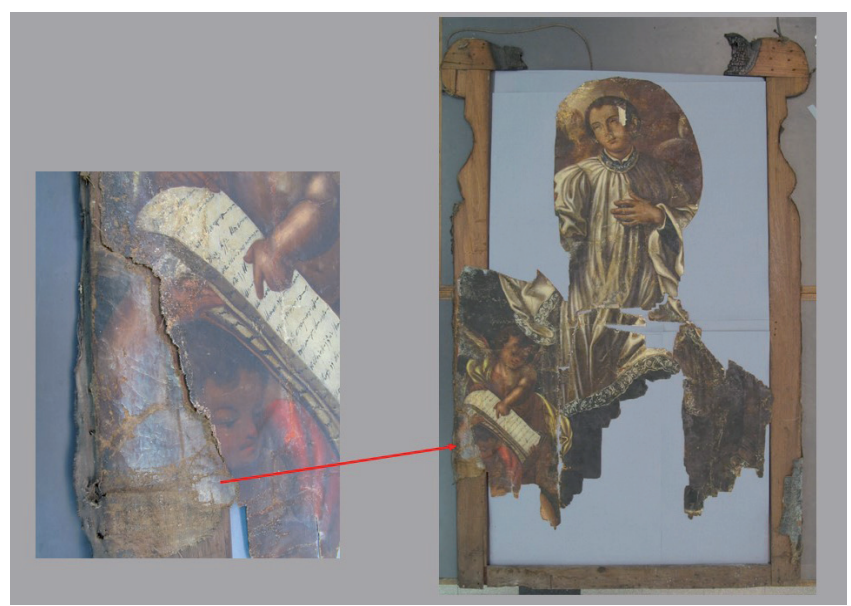

Figura 4.- Ubicación de los fragmentos de San Luis Gonzaga en el bastidor original.

Del mismo modo, la mínima intervención también involucró el acondicionamiento del bastidor en la recuperación de su función principal como soporte accesorio de la pintura. Se sospecha que durante los incendios de junio del 55 (O’Donnell 2006), el fuego consumió parte del bastidor y provocó una pérdida del 80 por ciento del cabezal superior. Afortunadamente los contornos sinuosos cercanos a los ensambles quedaron indemnes. En pos de conservar la materia como documento histórico y, en lugar de eliminar los restos dañados por el fuego, la madera carbonizada fue consolidada con una resina termoplástica en sucesivas aplicaciones, hasta obtener una superficie libre de carbón disgregado. La reintegración material del bastidor exigió la adaptación de un listón de madera de cedro copiando las formas remanentes para una óptima yuxtaposición. El anclaje de la nueva pieza fue reforzada con tarugos que permitían soportar la tensión del lienzo entelado manteniendo al mismo tiempo las propiedades de la planimetría características de la pintura de caballete y recuperando la disposición espacial de la imagen del santo dentro de los márgenes demarcados por el contorno ondulante del bastidor. [Figura 5]

Al igual que en la tela se extrajeron y analizaron muestras de la madera y a través de un examen microscópico se concluyó que la misma pertenece a una angiosperma es decir un árbol

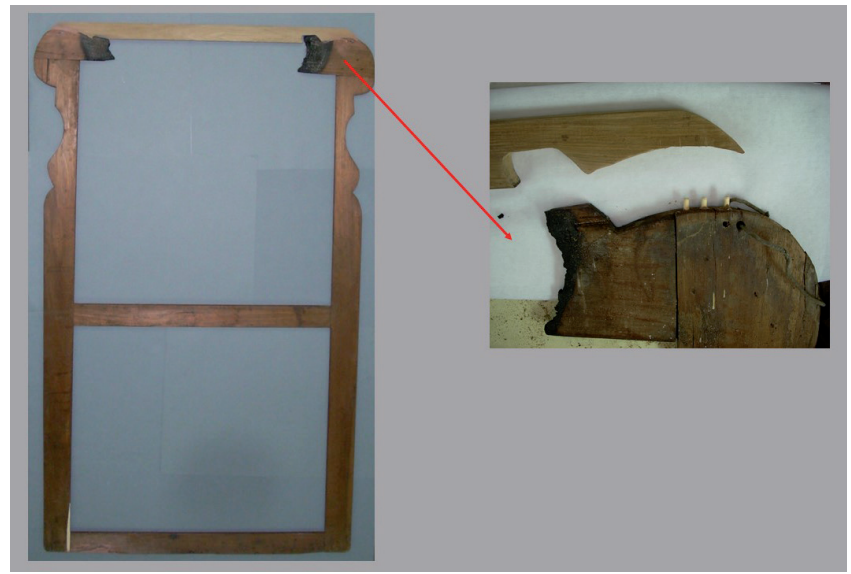

Figura 5.- Bastidor original luego de la intervención y detalle la esquina durante el tratamiento. con hojas, flores y fruto. Este dato aportado por la presencia de poros, complementado con las demás características que se observaron, apuntan al Cedro Americano (Cedrela Odorata) originario de América Central encontrándose también en América del Sur en la llamada selva de montaña, reducida en nuestro país a la "selva misionera". Todo apuntaría a que nos encontramos con un ejemplar de esta especie denominado comúnmente "cedro paraíso" o "cedro de hojas chicas", característicos por sus folíolos pequeños, marcadamente asimétricos, acuminados, glabros, con largos pecíolos generalmente mayores a $5 \mathrm{~mm}$ longitud. Los escasos ejemplares argentinos herborizados de esta especie según Buchinger \& Falcone se encuentran solamente en Misiones con una localización muy restringida. Posteriormente, es también citada para el Noroeste del país, sin embargo en la revisión de ejemplares de herbario no se detecta su presencia en esa región (Buchinger \& Falcone 1957).

Más allá de la identificación de la especie y al margen del listón quemado, era llamativo el buen estado de conservación del resto de la estructura. Si se consideran los factores ambientales desfavorables a los cuales estuvo sometido, sumado al abandono y descuido, la madera no presentaba signos de ataque biológico ni tampoco deformaciones. Estas características nos invitaron a pensar en la precisa selección y tratamiento de las maderas de los hacederos, como material primordial de sostén. Entre sus propiedades encontramos que es una madera con una densidad moderadamente ligera. La contracción volumétrica es de $0,34 \%$ lo cual la hace una madera muy estable y sin tendencia a deformarse pero poco resistente al fuego. La albura es blanca rosada y el duramen marrón rosado a rojo que oscurece por efecto de la luz, contiene además una resina aromática que ahuyenta a los insectos. La fibra es recta, ligeramente entrelazada y de grano medio. Es considerada una madera semiblanda de aserrado y cepillado fácil. No presenta problemas para ser encolada, ni tampoco para el clavado o entarugado. La madera es fácil de trabajar, es resistente tanto a la pudrición en contacto con el suelo como altamente repelente a las termitas (Cintron 2016). Todas estas cualidades la vuelven ideal para su uso en carpintería y ebanistería y no cabe duda que, ya en ese momento, los artesanos responsables de los retablos lo sabían. Cabe además señalar que su procedencia misionera coincide, obviamente, con el asentamiento de las misiones jesuíticas, desde donde se distribuían tanto imágenes como materiales hacia otros conventos, estancias o iglesias de la Orden.

Con todos estos datos podemos especular entonces que el lienzo utilizado en la obra de San Luis Gonzaga fue importado de Europa pero que el bastidor fue confeccionado en estas latitudes. La procedencia de la madera lo confirma como así también su intrincada silueta que coincide con el marco de su correspondiente altar. Es difícil imaginar que con el complejo sistema de lienzos corridos se hubiera encargado la hechura de este bastidor fuera de un radio muy lejano al templo de San Ignacio. Probablemente los mismos tallistas de los retablos de la iglesia confeccionaron el bastidor de San Luis para que luego el artista tensara el lienzo para pintar. Asimismo, un dato interesante fue el que arrojaron los retazos de tela que 
quedaron adheridos al soporte accesorio y que exhiben una prueba irrefutable. La base de preparación llega justo al límite del contorno del bastidor y asimismo los pliegues del lienzo acompañan las complejas curvas. Esto indicaría que la tela fue tensada, preparada y pintada en el mismo bastidor descartando por completo la posibilidad de que la obra hubiera sido encargada en otro sitio y luego tensada en el lugar de exhibición, algo muy frecuente al inicio de la colonia y registrado en reiteradas oportunidades en muchas pinturas restauradas de la Fundación Tarea (Bustillo 1994: 29).

\section{La pintura de San Juan Nepomuceno}

Recuperado el lienzo de San Luis Gonzaga la atención se centró luego, en el altar adyacente. Dentro del nicho de este altar se encontraba olvidada y escondida la obra de San Juan Nepomuceno. El deterioro era por supuesto mucho menor al de San Luis. Sin embargo un desprendimiento generalizado de la capa pictórica ponía en grave riesgo la integridad de la imagen. El húmedo escondite donde había reposado durante décadas colaboró para que esta situación se agravara. Paralelamente, el accionar del mecanismo de tramoya del nicho había provocado tajos y roturas en la tela. Tanto la fricción como el forzado desplazamiento del cuadro generaron estos daños. Por su parte, un manto de polvo y el barniz completamente decolorado ocultaban sensiblemente a Juan de Pomuk, bohemio de nacimiento vistiendo la sotana negra con sobrepelliz y rodeada su cabeza con una aureola de cinco estrellas. La historia atribuye la causa de su martirio a la negación de revelar al rey Wenceslao la confesión de su penitente, la reina Juana. Su culto como patrono de los confesores fue difundido especialmente por los jesuitas y es por ello la importancia de su altar en la Iglesia de San Ignacio (Schenone 1992: 532).

En cuanto a la restauración de la obra, como primera medida fue necesario realizar una consolidación de toda la superficie pictórica que implicó un largo tiempo de trabajo (cf. Scicolone 2002). Una vez asegurada la pintura se pudo trabajar por el reverso en donde optando nuevamente por una mínima intervención, la tarea involucró la remoción de una gruesa capa de tierra acumulada sobre la tela, la corrección de deformaciones del lienzo, el arreglo de cortes y tajos y el acondicionamiento del bastidor. [Figura 6].

En esta instancia se pudo analizar el soporte, que comparado con aquel de San Luis Gonzaga, se delata como un tejido más rústico. Aún cuando en el San Juan también fue identificada la fibra de lino, por microscopía óptica, la presencia de nudos e irregularidades de los hilos otorgan una apariencia menos refinada. La trama es moderadamente abierta, de ligamento plano con un entrecruzamiento simple de $1 \times 1$. Los hilos de la urdimbreson más delgadosquelos de la trama con una densidad que oscila entre 90 y 100 hilos $/ \mathrm{cm}^{2}$. En cuanto a la estructura, en este caso también, el soporte pictórico está formado por dos piezas verticales unidas mediante una costura manual con punto atrás que deja los orillos libres por el reverso de la obra. [Figura 7]. Palomino propone el proceso de la siguiente manera, “(...) y antes que se seque el aparejo del lienzo si el lienzo tuviere
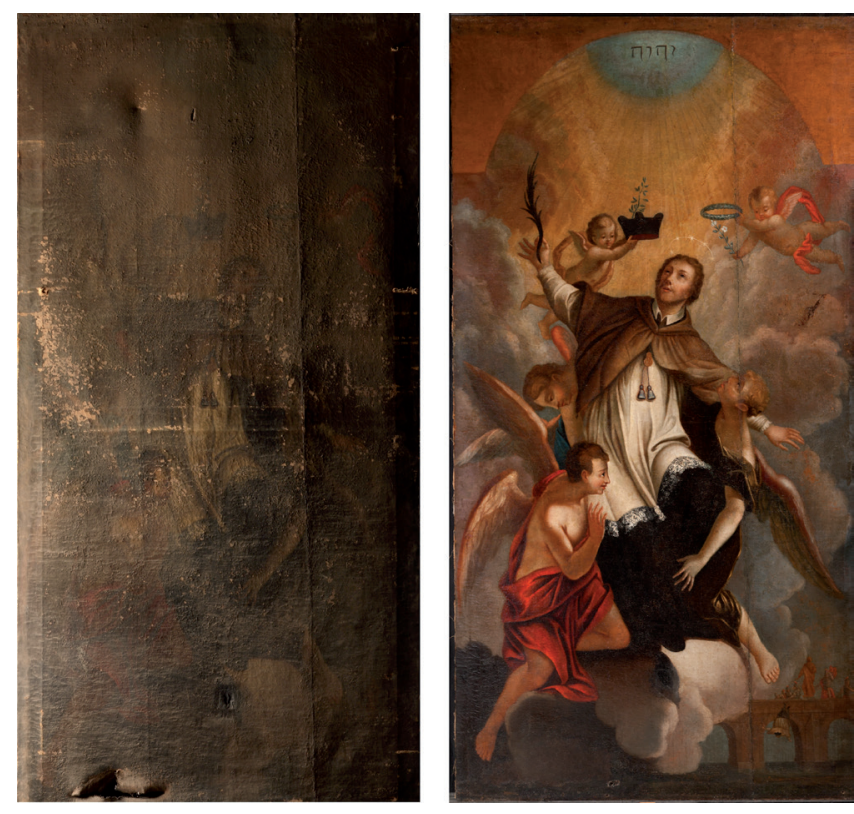

Figura 6.- Antes y después de la intervención de San Juan Nepomuceno. (IIPC-TAREA)

costuras se han de sentar con martillo suavemente llevando por debajo una moleta, con lo cual quedan bien disimuladas" (Palomino 1944: 51). Al mismo tiempo que relevábamos las costuras, la atención se detuvo también en el apresto del lienzo de San Juan. En primera instancia, había resultado llamativa la integridad manifestada por las fibras extraídas durante los procedimientos de lavado y disgregado para su preparación y extendido. Generalmente cuando se realiza este proceso, en obras de cierta antigüedad, las fibras se fragmentan durante su separación e inclusive en algunos casos se disgregan de manera tal que se hace difícil su identificación morfológica. En el lienzo del santo existía un apresto probablemente protector que, asimismo, era sensiblemente visible en ambas caras de la tela, de color blancuzco opalino y que Palomino lo describe como aparejo a la gacha de la siguiente forma:

"La primera mano de aparejo que se le ha de dar suele ser en dos maneras; la una y más antigua, es de gacha: esta se hace cociendo el agua a proporción de lo que es menester, y echándole después su harina de trigo bien cernida por cedazo delgado, y bien despolvoreada fuera del fuego, sin dexar de manearla, hasta que esté como un caldo espeso; y algunos le echan después un poco de miel, y un poco de aceyte de linaza a discreción, meneándola hasta que vaya trabando y tomando punto, sin que le queden gurullos; y con esta se le da la primera mano al lienzo con una cuchilla, o imprimadera de chapa de hierro... y con esta imprimadera se ha de ir tendiendo la gacha, y apurándola de suerte que no quede cargada, sino que tape los poros todos del lienzo y descubra los hilos, porque lo cargado hace cascarilla, y salta con el tiempo (...) (Palomino 1944: 50)".

Para determinar la presencia del almidón, uno de los métodos más simples para la identificación cualitativa es la reacción del mismo con el denominado reactivo de Lugol. La reacción positiva produce el viraje del color del reactivo, que inicialmente es pardo y se torna violeta azulado muy oscuro (Barton 2007: 1753). 


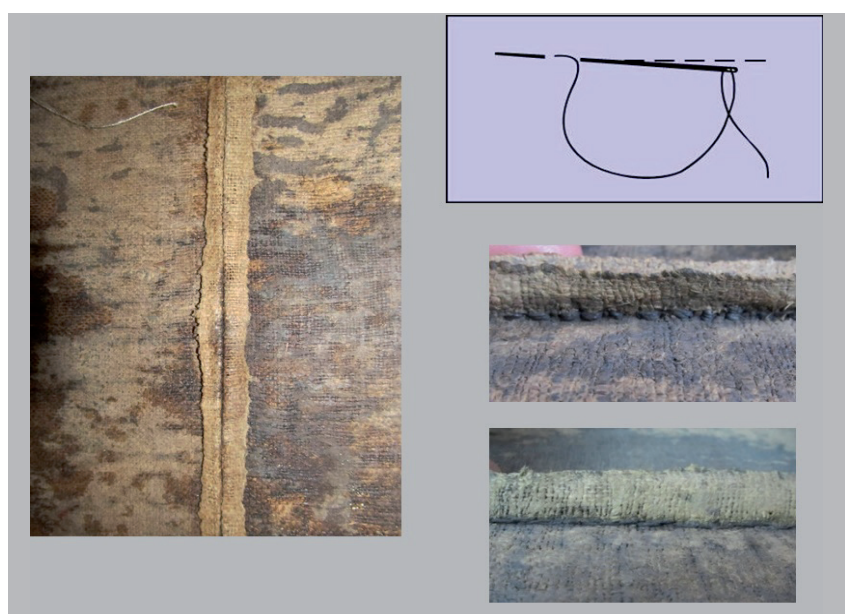

Figura 7.- Detalle de la costura manual de la obra de San Juan Nepomuceno con punto atrás que deja los orillos libres por el reverso de la obra

Realizamos la prueba con este protocolo y aun cuando la muestra cambió de color, el resultado no fue concluyente. La incógnita, aunque casi resuelta, necesita de una nueva identificación del material acorde a una metodología más precisa relativa a la identificación de sustancias orgánicas. Conocer las prácticas pictóricas de aquel momento resulta indispensable y San Juan Nepomuceno brinda un conjunto considerable de esas prácticas. Durante los primeros años de la Fundación TAREA se encontraron casos en donde los artistas preparaban las telas fuera y luego las cortaban para tensar mientras que en otras oportunidades los lienzos se preparaban en el bastidor definitivo (Bustillo 1998: 22). En el caso de nuestro santo hay apresto a lo largo de todo el orillo concluyendo entonces que la pieza fue aparejada primero y luego cosida antes de ser tensada con tachuelas de forja por sus lados y adherida en los extremos del bastidor definitivo. Éste último es de sección rectangular compuesto por 5 miembros sin biselar, con ensambles a media madera, encolados y tarugados. Es interesante destacar que, a pesar de ser un bastidor fijo cumple, en la actualidad, su función de sostén manteniendo el lienzo con una óptima tensión.

Siguiendo el proceso, se analizaron las muestras de la madera observando en los distintos macerados fibras de paredes medias con lumen visible, puntas con areola circular y abertura lenticular inclusa en posición opuesta y alterna. Los especialistas, luego del examen microscópico concluyeron, que en este caso se trataba de una caoba (Swietenia macrophylla) y que junto con la Cedrela pertenecen a la misma familia de Meliaceae. Una madera muy preciada que Europa no conoció hasta el descubrimiento de América y que luego fue ampliamente codiciada debido a su belleza, calidad y facilidad para trabajar. Es asimismo durable, de fácil secado y moderadamente resistente al contacto con el suelo, Su duramen rojizo o amarillo que oscurece al secarse, es resistente a la pudrición y al ataque de termitas. Tiene una superficie brillante y lisa al tacto, luego de cepillarla, es moderadamente liviana y dura. Se desarrolla en los bosques clasificados como "tropical seco" que se extienden desde el sur de México hasta Bolivia y Brasil (cf. Little y Wadsworth 1964).

\section{Conclusiones y perspectivas}

Para terminar, podemos afirmar que los soportes de San Luis Gonzaga y San Juan Nepomuceno, a pesar de los avatares sufridos, se han mantenido en buen estado de conservación, sin duda, por la calidad de sus materiales constitutivos. Por un lado, el lino de los lienzos ha perdurado firme y flexible orientándonos a pensar que fueron telas importadas de Europa ya que en esta zona no existían textiles de esa manufactura. Dentro de la larga trayectoria que tiene TAREA en lo que se refiere a restauración de pintura colonial, fue llamativo encontrar que estas telas no fueran lienzos de tejidos rústicos ni artesanales, sino más bien aparentaban ser textiles elegidos especialmente para pintar. Tampoco se trataba de telas de algodón o lienzos reciclados que hubieran sido utilizadas en tapicería, como se han descubierto en muchas ocasiones. Menos aún, textiles deteriorados con agujeros y costuras que delataban un origen ajeno a prácticas pictóricas pero que son muy frecuentes en la pintura colonial de esta región. Queda sin embargo confirmar el origen del apresto aplicado y la influencia del mismo en la preservación de las fibras.

Por otro lado, los bastidores de las dos pinturas hacen alarde de su óptimo estado y todo indica que la calidad de la madera tuvo una influencia directa. Presumimos que ambas estructuras fueron confeccionadas en esta región, no solamente por la procedencia de la materia prima sino también por tratarse de obras que pertenecen a retablos de tramoya y esto exige emplazar las pinturas antes de finalizar la construcción del retablo. Las excelentes propiedades tanto del cedro como de la caoba y la cuidada confección inducen a pensar que aquellos artesanos y ebanistas que llevaron a cabo los altares fueron también quienes construyeron los bastidores utilizando la misma madera con que erigieron los retablos. En este sentido también, el hallazgo de estas piezas fue inusitado ya que los bastidores, hasta ese momento relevados en estas latitudes, son siempre estructuras sencillas compuestas de listones finos y de terminaciones de aserrado manual con acabado muy rústico. En muchas ocasiones las varillas, dado su escaso espesor, se encuentran alabeadas. Asimismo las esquinas suelen estar pegadas artesanalmente o con refuerzos muy rudimentarios que delatan una confección sencilla y con herramientas muy rudimentarias, completamente diferente a los dos casos analizados. Finalmente, los indicios que manifiestan que las pinturas fueron llevadas a cabo en sus respectivos bastidores, ubicaría temporalmente las obras en una fecha cercana a la confección de sendos retablos, ambos datados en la primera mitad del siglo XVIII.

Siempre es difícil hacer afirmaciones contundentes, pero muchas veces los análisis de laboratorio dan claves que ayudan a dilucidar orígenes y prácticas confirmando de manera fundada las hipótesis planteadas por las otras disciplinas. Con todo, la conservación y la restauración suponen y exigen una comprensión profunda de las obras, de los estilos y de las épocas sumada a la aplicación de metodologías con base tecnológica y habilidad manual manteniendo al mismo tiempo rigor artístico y analítico. 
Es de esa manera que se puede establecer un diagnóstico y su posterior intervención, definiendo los procedimientos más adecuados para llevar adelante la tarea. La tecnología de la restauración abarca distintos campos y uno de ellos es el estudio material para determinar metodologías a aplicar. Esta instancia sin la ayuda de la física y la química sería improbable. De la misma forma, la obtención de los resultados sin la contextualización histórica se volvería estéril y sin fundamentos.

Es decir que la conservación-restauración requiere siempre de un enfoque interdisciplinario. Los datos aportados por la física, la química y la historia del arte completan y enriquecen la tarea del conservador. Asimismo, gracias a ese cruce de datos adquiridos de las distintas disciplinas es que se logra un resultado integral que acrecienta el conocimiento de todas las áreas participantes. De otra manera la ganancia se reduciría a un cúmulo de datos técnicos inútiles que, con la carencia de contextualización, resumirían la labor a un trabajo mecánico y a una caracterización analítica de materiales.

\section{Notas}

[1] Esta investigación fue realizada en el marco de los proyectos PICT2011- 1327 (Agencia Nacional de Promoción Científica) y Diálogo entre las Ciencias (UNSAM) de Argentina.

[2] Archivo General de la Nación. Buenos Aires, División Colonia, Secc. Gobierno, Colegio de San Ignacio, 1767-1775; fol. 385.

\section{Bibliografía}

BARTON, H. (2007), "Starch residues on museum artefacts: implications for determining tool use", Journal of Archaeological Science 34. Elsevier, 1752- 1762.

BERGER, G. (2000), Conservation of Paintings. Research and Innovations. London. Archetype Publications. 2000.

BONET BLANCO, M. C. (2001). “El retablo barroco escenografía e imagen". En Actas de simposio El Monasterio del Escorial y la pintura. Madrid, 623-642.

BRUQUETAS GALÁN, R. (2002) Técnicas y materiales de la pintura española en los siglos de oro. Madrid: Fundación de Apoyo a la Historia del Arte Hispánico.

BUCHINGER, M., FALCONE, R. (1957). "Las Meliáceas argentinas". Revista de Investigaciones Forestales. Buenos Aires.

BURUCÚA, J. E. et. al. (2000). Tarea de diez años, Buenos Aires: Fundación Antorchas.

BUSTILLO, A. (1994), "Algunos aspectos del montaje de telas coloniales de la región sudamericana". En Abracor VII Seminario, noviembre 1994. Petrópolis.
BUSTILLO, A. (1998). "Estado de conservación, materiales, características del soporte, técnica pictórica y tratamiento". En Una serie de pinturas cuzqueñas de Santa Catalina: historia, restauración, química, Buenos Aires: Fundación Antorchas.

CIATTI, M. et. al. (2008).The restoration of one of the canvasses from the Palazzo Chigi in san Quirico d'Orcia: Notes on an "Impossible"Restoration. OPD Restauro. Suplement with english text. Firenze: OPD.

CINTRON, B. "Research and Development Search", United States Department of Agriculture, Forest Service en www. Fs.fed.us/global/ iitf/Cedrelaodorata.pdf US FOREST SERVICE. [consulta 04/06/2016].

DEL ZOTTO, F. (1990). “Preservation of canvas paintings: structural solutions in relation to environmental changes", ICOM, Preprints of the $9^{\text {th }}$ Triennial Meeting, Dresden.

GORDON COOK, J. (1993). Handbook of Textile Fibres. I Natural Fibres, Durham: Merrow.

GREAVES, P.H; SAVILLE, B.P. (1995). Microscopy of textile fibres, Londres: Bios Scientific Publishers Limited.

JÁUREGUI, A., PENHOS, M. (1999). "Las imágenes en la Argentina colonial. Entre la devoción y el arte". En Nueva historia argentina. Arte, sociedad y política, ed. Burucúa. Buenos Aires: Sudamericana.

KIRBY, J., (2005). "Fuentes para la comprensión: Por qué una obra de arte es como es". Acta del II Congreso de GEICC Investigación en conservación y restauración, Barcelona.

LITTLE, E.L., Jr., WADSWORTH, F.H. (1964). Common trees of Puerto Rico and the Virgin Islands. Agriculture Handbook No. 249, U.S. Department of Agriculture, Forest Service.

MECKLENBURG, M. (1982). "Some aspects of the mechanical behavior of fabric-supported paintings". Report to the Smithsonian Institution. 12-15.

MECKLENBURG, M., TUMOSA, C. S. (1991) b. "Mechanical behavior of paintings subjected to changes in temperature and relative humidity". In Art in transit, ed. M. F. Mecklenburg. Washington, D.C.: National Gallery of Art.172-214.

MEHRA, V. R. (2001). Foderatura a freddo: $i$ testi fondamentali per la metodologia e la pratica, Firenze: Nardini.

MORALES, A. et al. (2016). "Alternative methodology for traditional interventions: A colonial painting and its lining with the nap bond method", Journal of Cultural Heritage 18, Elsevier. 362-365.

O'DONNELL, P. (2006), El conflicto entre Perón y la Iglesia, Diario La Nación, Buenos Aires, Argentina.

PALOMINO, A. (1944); [1 ${ }^{\text {a }}$ ed. 1715-1724]. Museo pictórico y escala óptica, Buenos Aires: Poseidón.

PERCIVAL-PRESCOTT, W. (2003). "Introduction". En Lining Paintings. Papers from the Greenwich Conference on comparative lining Techniques. London: Archetype. 
RIBERA, A.; SCHENONE, H. (1944). "Los lienzos corredizos y breve noticia del pintor Miguel Aucell", Archivum, Tomo II Cuaderno 2, Buenos Aires.

ROCHE, A. (2003). "Approche du príncipe de reversibilité des doublages des peintures sur toile". Studies un conservation (IIC), London: James \& James, Ltd . Volume 48 Number 2.

ROSTAIN, E. (1981). Rentoilage et transposition des tableaux. Puteaux: Erec.

SCHENONE, H. (1992). Iconografía del arte colonial. Los Santos. Buenos Aires: Fundación Tarea.

SCICOLONE, G.(2002). Restauración de la pintura contemporánea. De las técnicas de intervención tradicionales a las nuevas tecnologías. Sevilla: Nerea.

SPERONI, P. (2005). “Minimo intervento Conservativo nel Restauro dei Dipinti". En Cesmar7. Atti del Secondo Congresso Internazionale "COLORE E CONSERVAZIONE - Materiali e Metodi nel Restauro delle Opere Policrome Mobili", Padova: Casa Editrice II Prato.
VICENS VIVES, J., (ed.), (1972). Historia de España y América social y económica, vol. IV, Barcelona: Vicens Vives.

VILLARQUIDE JEVENOIS, A. (2005). La pintura sobre tela II. Sevilla: Nerea.

VILLERS, C., (ed.), (2000). The Fabric of Images. European Paintings on Textile Supports in the Fourteenth and Fifteenth Centuries, London: Archetype.

VILLERS, C., (ed.). (2003). Lining Paintings. Papers from the Greenwich Conference on comparative lining Techniques. London: Archetype.

WEDDIGEN, E. (2005). Introduzione alle relazioni sul minimo intervento a Thien. Cosa significa Minimal Intervention?". En Minimo intervento Conservativo nel Restauro dei Dipinti. Cesmar7. Atti del Secondo Congresso Internazionale COLORE E CONSERVAZIONE - Materiali e Metodi nel Restauro delle Opere Policrome Mobili, 29-30 Ottobre 2004, Teatro Comunale, Thiene (VI), Padova: Casa Editrice II Prato.

YOUNG, C. (2012). “History of fabric supports”, en Stoner J. H., Rushfield R., ed., Conservation of easel paintings. London: Routledge.

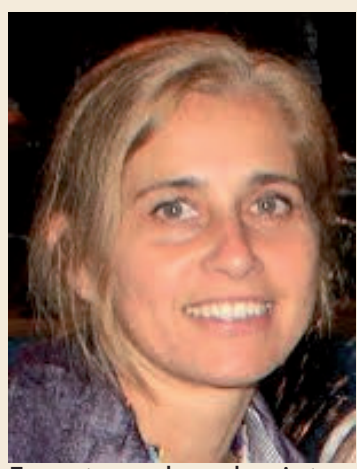

\section{Damasia Gallegos}

damagallegos@gmail.com

Instituto de Investigaciones sobre Patrimonio Cultural. Universidad Nacional de San Martín. Quinquela Martín 1784, CABA. Argentina

Es restauradora de pintura de caballete y pintura mural y magister en Historia del Arte Argentino y Latinoamericano (IDAESUNSAM). Actualmente es Directora del Centro Tarea perteneciente al Instituto de Investigaciones sobre el Patrimonio Cultural de la Universidad Nacional de San Martin en Buenos Aires, Argentina. Profesora Adjunta en la Licenciatura y en la Maestría en Conservación y Restauración del Patrimonio artístico y bibliográfico del IIPC-TAREA. Ha sido profesora invitada en el Opificio delle Pietre Dure e Laboratorio di Restauro en Florencia, Italia. Fue asesora e instructora en el Programa de Rescate de Bienes Culturales organizado por la Dirección Nacional de Patrimonio y Museos de la Secretaría de Cultura de la Nación Argentina. Autora de artículos en revistas y publicaciones de conservación nacionales e internacionales. 


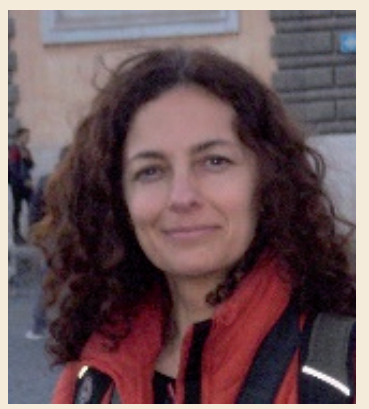

\section{Ana María Morales}

anitamo40@hotmail.com

Instituto de Investigaciones sobre Patrimonio Cultural. Universidad Nacional de San

Martín. Quinquela Martín 1784, CABA. Argentina

Desde 1998 es conservadora y restauradora de pintura de caballete y obras sobre papel. Actualmente trabaja en el Instituto de Investigaciones sobre el Patrimonio Cultural -Tarea de la Universidad Nacional San Martín, y en el Museo Histórico Nacional, Argentina. En esa misma universidad es docente y participó en proyectos de investigación. Ha sido becada por ICCROM, AECID y el Ministerio de Bienes Culturales de Italia para participar de cursos de perfeccionamiento profesional. Es autora de publicaciones nacionales e internacionales.

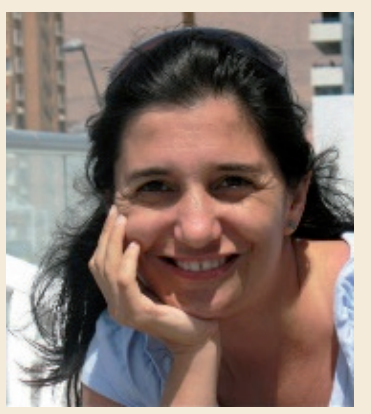

\section{Dolores González Pondal}

dologp@hotmail.com Instituto de Investigaciones sobre Patrimonio Cultural. Universidad Nacional de San Martín. Quinquela Martín 1784, CABA. Argentina

Desde el año 2009 se desempeña como restauradora en el Centro TAREA del Instituto de Investigaciones para el Patrimonio Cultural de la Universidad Nacional de San Martín. Además es docente en la Maestría en conservación de la misma Universidad. Es alumna avanzada en la Maestría de Historia del Arte Argentino y Latinoamericano en IDAES, UNSAM. Participa en proyectos de Investigación como así también de cursos de formación profesional constantemente.

Durante los años 1993 a 1997 perteneció al staff de restauradores de la Fundación T.A.R.E.A. En el año 1996 fue becada por la misma institución para asistir al "Curso de especialización en Pintura de Caballete" en el Instituto del Patrimonio Histórico Español. En el año 1997 fue becada por el Ministerio de Cultura de España para realizar una estancia en el Museo Reina Sofía de la ciudad de Madrid. En 1998/ 1999 fue becaria de la fundación Antorchas para realizar el Curso de Conservación Preventiva de Museos patrocinado por el Smithsonian Institute. 


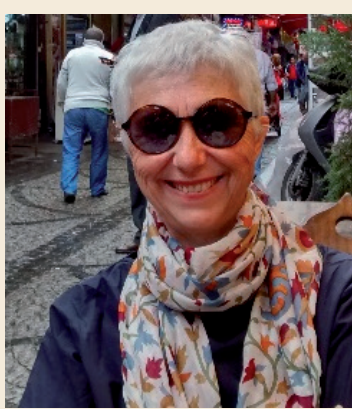

\section{Gabriela Siracusano}

gasiracusano@gmail.com

Centro de Investigación en Arte, Materia y Cultura (IIAC-UNTREF), Sede Museo de la Inmigración. Argentina

Gabriela Siracusano es Doctora en historia del arte por la Universidad de Buenos Aires, especializada en arte colonial sudamericano. Como Investigadora Principal de carrera del CONICET, realiza y dirige numerosos proyectos de investigación interdisciplinarios sobre la dimensión material de las producciones artísticas. Es directora del Centro de investigación en Arte, Materia y Cultura de la Universidad Nacional de Tres de Febrero. Profesora Titular regular de la Carrera de Artes (UBA). Durante 2009 y 2013 fue Directora Académica del Instituto de Investigaciones sobre el Patrimonio Cultural (IIPC-UNSAM). Es 2003-2004 Getty Postdoctoral Fellow y 2006-2007 John Simon Guggenheim Fellow. Es profesora y conferencista invitada de numerosas universidades extranjeras. De 1997 a 2007 se desempeñó como Presidente de CAIA. Getty Scholar 2016. Autora de varios libros y artículos, entre los que se destacan El Poder de los colores (Buenos Aires, FCE, 2005; Premios ALAA y AACA), Pigments and power in the Andes (London, Archetype, 2011) y La Paleta del espanto (Buenos Aires, Unsam edita, 2010)

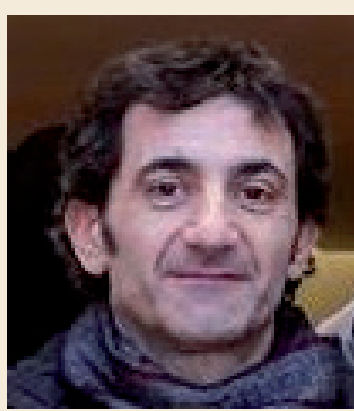

\section{Fernando Marte}

fmarte.iipc@gmail.com Instituto de Investigaciones sobre Patrimonio Cultural. Universidad Nacional de San Martín. Quinquela Martín 1784, CABA. Argentina

Fernando Marte, Graduado de Ingeniero Químico por la Facultad de Ciencias Exactas, Físicas y Naturales, Universidad Nacional de Córdoba (UNC). Doctor en Biología Molecular y Biotecnología por el Instituto de Investigaciones Biotecnológicas de Universidad Nacional de San Martín (UNSAM). Tomó cursos de especialización en conservación preventiva de Bienes Culturales con becas Fundación Bunge y Born y Fundación Antorchas. Luego realizó investigación científica aplicada a la conservación, durante dos años y medio, en el Smithsonian Center for Materials Research and Education, Washington DC, USA. Actualmente se desempeña como Profesor y Secretario de Investigación y Transferencia del Instituto de Investigaciones sobre el Patrimonio Cultural de la UNSAM. 